\title{
Toileting behavior and urinary tract symptoms among younger women
}

\author{
Johanna Sjögren $^{1} \cdot$ Lars Malmberg $^{1} \cdot$ Karin Stenzelius $^{1,2}$ (D)
}

Received: 4 October 2016 / Accepted: 14 March 2017 / Published online: 5 April 2017

(C) The Author(s) 2017. This article is published with open access at Springerlink.com

\begin{abstract}
Introduction and hypothesis Irregular or infrequent voiding due to avoiding school toilets can contribute to a number of urinary problems among school children. There is, however, a lack of studies on younger women. The aim of this study was to investigate toileting behavior and the correlation to lower urinary tract symptoms (LUTS) among young women (age 18-25 years). A further aim was to validate the Swedish version of the Toileting Behavior scale (TB scale).

Methods Quantitative descriptive design was used with two questionnaires: the International Consultation on Incontinence Questionnaire Female Lower Urinary Tract Symptoms (ICIQFLUTS) and the TB scale, together with six background questions. The questionnaires were distributed in November 2014 to 550 women aged $18-25$ years randomly selected from the population register in southern Sweden.

Results A total of 173 (33\%) women responded. Mean age was 21.6 years (range 18-25). The Swedish version of TB scale showed good construct validity and reliability, similar to the original. Most toileting behavior was significantly correlated with LUTS, which were common, as $34.2 \%$ reported urgency and $35.9 \%$ urine leakage at least sometimes or more often.

Conclusions LUTS were quite common in this group of young women. Toileting behaviors were also significantly related to urinary tract symptoms. Thus, TB scale was useful in
\end{abstract}

Karin Stenzelius

karin.stenzelius@mah.se

1 Urology Department, Skåne University Hospital, Jan Waldenströms gata 7, SE-205 02 Malmö, Sweden

2 Faculty of Health and Society, Malmö University, Jan Waldenströms gata 25, SE-205 06 Malmö, Sweden this population, and the translated Swedish version showed good construct validity and reliability.

Keywords Toileting behavior $\cdot$ Lower urinary tract symptoms (LUTS) $\cdot$ Voiding $\cdot$ Women $\cdot$ Young women

\section{Introduction}

It is well known that irregular or infrequent voiding due to avoiding school toilets is associated with a number of different problems among female children up to 18 years [1-5]. Bladder problems that manifest during childhood may predict problems such as overactive bladder $(\mathrm{OAB})$, urinary tract infections (UTIs), or incomplete bladder emptying in adulthood $[6,7]$. Insufficient privacy, lack of peace and quiet and essential hygiene products, and dirty conditions may result in the desire to void be ignored, thus causing infrequent voiding or low fluid intake $[8,9]$. Studies show that urinary incontinence (UI) and other lower urinary tract symptoms (LUTS) are common in women aged 25-90 years and tend to increase with age [10-16]. Wang and Palmer conducted a concept analysis of women's toileting behavior related to urinary elimination (5915 persons) [17]. Their result showed that urinary elimination can be defined as voluntary actions related to the physiological event of emptying the bladder, which comprises specific attributes, including voiding place, time, position, and style. This behavior also depended on physical and social environments (Fig. 1). From this theory, a questionnaire was developed and validated as the Toileting Behavior scale (TB scale) [18].

Understanding toileting behavior and symptom onset seems to be important for understanding female LUTS [17]. There is, however, a lack of studies on women aged 18-25 years. The question is whether the voiding pattern (place, 
Fig. 1 Theoretical framework for women's toileting behavior (Wang and Palmer [17])
Antecedents

Attributes toileting behaviour

Consequences

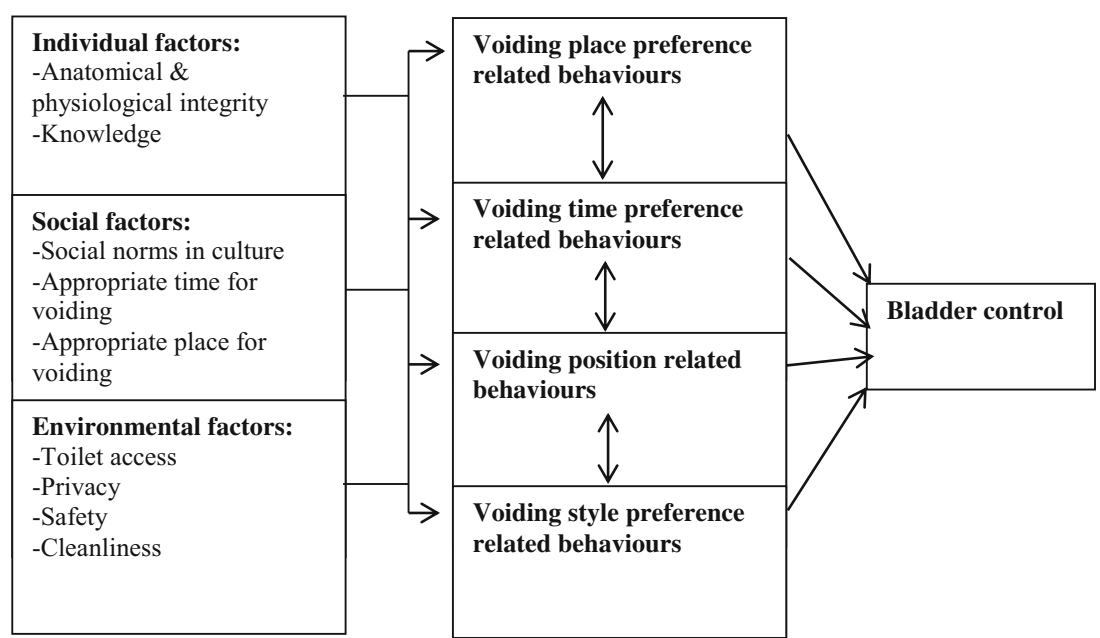

time, position, and style), established during elementary and secondary school routines, continues among younger women who have finished school. The aim of the study was to investigate toileting behavior and prevalence of LUTS based on the hypothesis that there are correlations between toileting behavior and LUTS among younger women (aged 18-25 years). A further aim was to validate the Swedish version of the TB scale.

\section{Materials and methods}

This was a quantitative descriptive design study using two assessment tools: the International Consultation on Incontinence Questionnaire - Female Lower Urinary Tract Symptoms (ICIQ-FLUTS), and the Toileting Behavior scale (TB scale), together with six background questions about age, height, weight, occupation, parity, and smoking habits. The TB scale consists of 19 questions with five response alternatives each: never (1), rarely (2), sometimes (3), often (4), always (5). It was tested for construct validity and internal consistency. The five subscales were premature voiding ( 5 items), straining during voiding (4 items), place preference for voiding (4 items), delayed voiding ( 3 items), and position preference for voiding (3 items) [18]. One question was expressed in a positive direction and was therefore recoded into the same negative direction as the other questions. Therefore, higher scores indicate a more dysfunctional behavior. Permission to use and translate the TB scale into Swedish was given by the constructors. KS, LM and two students at Malmö University did the translation. Experts had the opportunity to comment, and a back-translation was then done with a native English speaker, which resulted in a similar version. The questionnaire was tested in a pilot survey of 100 students at Malmö University and showed a small internal dropout rate, indicating the questions seemed to be easily understood.

ICIQ-FLUTS [19] - tested and translated into many languages including Swedish and with grade A level of validation according to International Continence Society (ICS) recommendations, was used with permission from its developers. It consists of 12 questions with subscales frequency (1-4), voiding (5-7), and urinary incontinence (8-12). Each question had five response alternatives [never (0), occasionally (1), sometimes (2), most of the time (3), all of the time (4)]. The question about day and night frequency and incontinence also had five response alternatives specified in numbers. Higher scores indicate greater impact of individual symptoms. Each question has a bother score from 0 (not at all severe) to 10 (extremely severe). Bother scales are not incorporated in the overall score but indicate the impact of individual symptoms for the patient.

Written information about the purpose of the study and the questionnaires were distributed in November 2014 to 550 women aged 18-25 years randomly selected from the population register in a county in southern Sweden. The information consisted of voluntary participation, the right to withdraw at any time without stating a reason, assurance that all data would be kept confidential, and details of whom to contact in case of questions. A reminder was sent after 3 months. The study was approved by local ethics committee of Lund University with reg. no. 2014/496.

\section{Statistical analyses}

Descriptive statistics were used with mean values and standard deviations (SD). When comparing nonparity with one parity or more, the calculation was performed with MannWhitney $U$ test, assuming data as being nonnormally distributed. The chi-square test was used when comparing living 
place between responders and nonresponders. Inspired by van Breda et al. [20], we summarized "sometimes," "often," and "always" as "at least sometimes" in the variables in the TB scale. Similarly, we summarised "sometimes," "most of the time, and "all of the time" as "at least sometimes" in ICIQFLUTS variables. These simplifications were also based on the fact that having symptoms sometimes or more often is different from having a symptom rarely or never.

Mean factor scores in the ICIQ-FLUTS and TB scale were estimated by first adding the scores and then dividing them by the number of items in each factor. Question number 18 in the TB scale was transformed to be in the same negative direction as the other items (i.e., higher scores indicating increasing dysfunctional behavior). Correlations between factors of the TB scale and the ICIQ-FLUTS were calculated using Spearman's rank correlation test and, $p$ values $<0.05$ were regarded as statistically significant. SPSS version 22.0 was used for all statistical calculations.

The TB scale instrument was tested by a principal component analysis with Varimax rotation, and the factor solution was based on Eigenvalues $>1$. Factor loadings $>0.4$ were set as a limit to fit into a factor. Internal consistency was measured with Chronbach's alpha.

\section{Results}

In total, 550 letters were sent; 26 were returned as address unknown. A total of 173 women responded, which gives a response rate of $33 \%$. Analysis of nonresponders showed that those living in a city had a tendency to a lower response rate than those living outside the cities $(p=0.06)$. The mean age was 21.6 years (range 18-25), and mean body mass index (BMI) 22.9 (range 17-38). In all, 26 were smokers (15.6\%). Of the whole sample, $85 \%$ (153) were nulliparous and $11.5 \%$ were parous (14 were uniparous and six multiparous). In total, 127 women were students in higher education, while 46 were employed. More than $95 \%$ completed all questions in the questionnaires.

\section{TB scale}

In all, $87.2 \%$ were worried about the cleanliness of public toilets at least sometimes, and $17.4 \%$ always avoided using them. To avoid using public toilets, $45.6 \%$ always emptied the bladder at home and $11.6 \%$ always tried to wait until they came home. In all, $46.5 \%$ at least sometimes emptied the bladder without desire at home and just in case. Premature voiding in a public place was reported by $3.6 \%$ often or always.

Delayed voiding because of business was reported at least sometimes by $69.9 \%$ of the women. The behavior of restraining the desire to void as long as possible occurred at least sometimes in $48.6 \%$, and $46.7 \%$ restrained the desire at work or school.

Straining voiding to initiate urinating at least sometimes was reported by $20.3 \%$ and during the whole urinating process by $12.7 \%$. To empty the bladder completely, straining while voiding at least sometimes was reported in $38.8 \%$ and completely in $42.2 \%$. Most women $(97.6 \%)$ sat down on the toilet at least sometimes. The behavior of hovering over the toilet occurred at least sometimes in $24.4 \%$ of women. Sitting in a squatting position to empty the bladder at least sometimes was reported by $4.2 \%$ (Table 1 ).

\section{ICIQ-FLUTS}

Thirty-two participants (19.3\%) reported nocturia two or more times. Concerning daytime micturition frequency: $50.9 \%$ of women voided more than nine times a day, $2.9 \%$ voided one to six times a day, and $46.2 \%$ voided seven to eight times a day: $34.2 \%$ reported having urgency and $21.1 \%$ pain at least sometimes. Hesitancy, straining, and intermittency at least sometimes was reported by $23.6,22$, and $13.9 \%$, respectively. Involuntarily loss of urine was reported by $35.9 \%: 27.2 \%$ once or less per week, $6.4 \%$ two or three times per week, and $2.3 \%$ once per day. None reported incontinence several times a day. Women who reported having any type of incontinence responded as follows: $32.5 \%$ (urge); $47.1 \%$ (stress), $23.6 \%$ (mixed), and $11.6 \%$ (unexplained). One women reported nocturnal enuresis (Table 2 ).

In relation to maximum scores, the most dysfunctional behaviors were place preference (14.5/20), delayed voiding (7.9/ $15)$, and premature voiding (10/25). The parity group of 20 women had significantly higher scores than nulliparous (143) in place preference and delayed voiding. Frequency and voiding had the highest urinary symptoms scores, and significantly higher scores were seen in all dimensions in the parity group (Table 3).

\section{TB scale correlations to ICIQ-FLUTS}

Spearman's correlation factor was slightly positive for all investigated parameters when the TB scale was compared with the ICIQ-FLUTS (0.060-0.620). The behavior of straining had the strongest correlation to frequency and voiding: (0.326) and (0.620), respectively. The strongest $p$ value was found for the correlation between TB subscales straining to void and premature voiding to all ICIQ-FLUTS subscales $(p<0.001-0.004)$. Four TB subscales - place preference for voiding, premature voiding, delayed voiding, and straining voiding-were significantly correlated with the ICIQFLUTS subscales frequency and voiding $(p<0.0001-$ 0.030). All TB subscales but place preference were significantly related to ICIQ-FLUTS incontinence subscale $(p<0.001-0.043)$ (Table 4). 
Table 1 Descriptive data of the Toileting Behavior (TB) scale: results for the five subscales

\begin{tabular}{|c|c|c|c|c|c|c|c|}
\hline Questions & & $\begin{array}{l}\text { Never } \\
{[n(\%)]}\end{array}$ & $\begin{array}{l}\text { Rarely } \\
{[n(\%)]}\end{array}$ & $\begin{array}{l}\text { Sometimes } \\
{[n(\%)]}\end{array}$ & $\begin{array}{l}\text { Often } \\
{[n(\%)]}\end{array}$ & $\begin{array}{l}\text { Always } \\
{[n(\%)]}\end{array}$ & $\begin{array}{l}\text { At least sometimes } \\
{[n(\%)]}\end{array}$ \\
\hline \multicolumn{8}{|l|}{ Place preference for voiding } \\
\hline Worry about sanity in public toilets & 1 & $4(2.3)$ & $19(11.0)$ & $44(25.6)$ & $43(25)$ & $62(36)$ & $149(87.2)$ \\
\hline Avoid public toilets & 2 & $10(5.8)$ & $36(20.9)$ & $51(29.7)$ & $45(26.2)$ & $30(17.4)$ & $126(72.8)$ \\
\hline Empty the bladder at home & 3 & $3(1.8)$ & $9(5.3)$ & $2(14.6)$ & $56(32.7)$ & $78(45.6)$ & $136(92.9)$ \\
\hline Try to wait until I come home & 4 & $6(3.5)$ & $35(20.3)$ & $70(40.7)$ & $41(23.8)$ & $20(11.6)$ & $131(76.1)$ \\
\hline \multicolumn{8}{|l|}{ Premature voiding } \\
\hline \multicolumn{8}{|l|}{ Void without desire: } \\
\hline At home & 5 & $42(24.4)$ & $50(29.1)$ & $48(27.9)$ & $26(16.1)$ & $6(3.5)$ & $80(46.5)$ \\
\hline At work/school & 6 & $78(45.3)$ & $52(30.2)$ & $24(14)$ & $16(9.3)$ & $2(1.2)$ & $72(24.5)$ \\
\hline In the home of someone else & 7 & $83(48.3)$ & $57(33.1)$ & $20(11.6)$ & $10(5.8)$ & $2(1.2)$ & $32(18.6)$ \\
\hline In a public place & 8 & $121(70.3)$ & $35(20.3)$ & $10(5.8)$ & $4(2.3)$ & $2(1.2)$ & $16(9.3)$ \\
\hline "Just in case", preventive purpose & 9 & $47(27.3)$ & $45(26.2)$ & $47(27.3)$ & $24(14)$ & $9(5.2)$ & $80(46.5)$ \\
\hline \multicolumn{8}{|l|}{ Delayed voiding } \\
\hline Try to delay voiding if I'm busy & 10 & $17(9.9)$ & $34(19.8)$ & $72(41.9)$ & $39(22.7)$ & $10(5.8)$ & $121(70.4)$ \\
\hline Restrain the desire as long as possible & 11 & $30(17.4)$ & $59(34.1)$ & $57(32.9)$ & $25(14.5)$ & $2(1.2)$ & $84(48.6)$ \\
\hline Restrain the desire at work/school & 12 & $34(19.7)$ & $58(33.5)$ & $54(31.2)$ & $19(11.0)$ & $8(4.5)$ & $81(46.7)$ \\
\hline \multicolumn{8}{|l|}{ Straining voiding } \\
\hline To initiate the urinating & 13 & $91(52.6)$ & $47(27.2)$ & $29(16.8)$ & $5(2.9)$ & $1(0.6)$ & $35(20.3)$ \\
\hline During the whole urinating process & 14 & $111(64.2)$ & $40(23.1)$ & $18(10.4 \%)$ & $3(1.7)$ & $1(0.6)$ & $22(12.7)$ \\
\hline To empty the bladder completely & 15 & $68(39.3)$ & $38(22)$ & $42(23.4)$ & $15(8.7)$ & $10(5.8)$ & $67(38.8)$ \\
\hline To empty the bladder faster & 16 & $56(32.4)$ & $44(25.4)$ & $56(32.4)$ & $14(81)$ & $3(1.7)$ & $73(42.2)$ \\
\hline \multicolumn{8}{|l|}{ Position preference for voiding } \\
\hline Sit down on the seat & 17 & $1(0.6)$ & $3(1.7)$ & $7(4)$. & $33(19.1)$ & $129(74.6)$ & $169(97.6)$ \\
\hline Hover over the toilet & 18 & $70(40.7)$ & $60(34.9)$ & $33(19.2)$ & $5(2.9)$ & $4(2.3)$ & $42(24.4)$ \\
\hline Squat on the toilet & 19 & $153(89.4)$ & $11(6.4)$ & $2(1.2)$ & $3(1.8)$ & $2(1.2)$ & $7(4.2)$ \\
\hline
\end{tabular}

Mean dropout for each question was 0.73 (range 0-2)

Principal component analysis with Varimax rotation revealed five underlying factors that explained $66 \%$ of the variance. This factor solution was in agreement with the developers of the questionnaire. Cronbach's alpha values within each factor were satisfactory $(0.71-0.84)$ and similar to the original, except for position preference, which had a Cronbach's alpha of 0.54 compared with 0.73 in the original [18] However, the Swedish version was supplemented with one question in this category (Table 5).

\section{Discussion}

The hypothesis in our study was corroborated, as there were significant relations between toileting behavior and LUTS among younger women. This is an interesting finding and could have important clinical implications. For example,
Moore et al. found that residual urine increased by $149 \%$ in those who hovered over the toilet instead of sitting in a relaxed position [22]. However, the population in that study were older (25-81 years). In our study, most women usually sat on the toilet. The most frequent behaviors were within the factors place preferences (i.e., avoiding toilets) and different strategies to delay voiding. Most study participants were students or worked and thus could avoid public toilets, even though a majority were worried about the cleanliness of public toilets in, e.g., shopping centers, petrol stations, restaurants, or pubs.

There seems to be a lack of knowledge among young and middle-aged women about a normal way of emptying the bladder; for instance, avoiding straining when voiding [23]. It is not clear what impact straining has on voiding dysfunction [23-25]. However, symptoms connected to the emptying phase often coexist with symptoms correlated to the storage 
Table 2 Prevalence of lower urinary tract symptoms (LUTS) among younger women

\begin{tabular}{|c|c|c|c|c|c|c|c|}
\hline Variable & Bother score & $\begin{array}{l}\text { Never } \\
\mathrm{n}(\%)\end{array}$ & $\begin{array}{l}\text { Rarely } \\
\mathrm{n}(\%)\end{array}$ & $\begin{array}{l}\text { Sometimes } \\
\mathrm{n}(\%)\end{array}$ & $\begin{array}{l}\text { Often } \\
\mathrm{n}(\%)\end{array}$ & $\begin{array}{l}\text { Always } \\
\mathrm{n}(\%)\end{array}$ & $\begin{array}{l}\text { At least sometimes } \\
\mathrm{n}(\%)\end{array}$ \\
\hline Frequency (4) & 1.54 & & & & & & \\
\hline Nocturia*,a $^{*}$ & 1.08 & $69(41.3)$ & $66(39.5)$ & $23(13.8)$ & $8(4.8)$ & $1(0.6)$ & $32(19.3)$ \\
\hline Urgency* & 1.72 & $46(27.5)$ & $64(38.3)$ & $38(22.8)$ & $16(9.6)$ & $3(1.8)$ & $57(34.2)$ \\
\hline Pain* & 1.33 & $100(60.2)$ & $31(18.7)$ & $24(14.5)$ & $7(4.2)$ & $4(2.4)$ & $35(21.1)$ \\
\hline Daytime $^{\mathrm{b}}$ & 2.04 & $5(2.9)$ & $80(46.2)$ & $79(45.7)$ & $8(4.6)$ & $1(0.6)$ & $88(50.9)$ \\
\hline Voiding (3) & 1.28 & & & & & & \\
\hline Hesitancy & 1.10 & $60(34.7)$ & $72(41.6)$ & $31(17.9)$ & $7(4.0)$ & $3(1.7)$ & 41 (23.6) \\
\hline Straining & 1.09 & $98(56.6)$ & $37(21.4)$ & $32(18.5)$ & $3(1.7)$ & $3(1.8)$ & $38(22)$ \\
\hline Intermittency & 0.75 & $107(61.8)$ & $42(24.3)$ & $17(9.8)$ & $6(3.5)$ & $1(0.6)$ & $24(13.9)$ \\
\hline Incontinence (5) & 0.59 & & & & & & \\
\hline Urge & 0.98 & 117 (67.6) & 34 (19.7) & $20(11.6)$ & $1(0.6)$ & $1(0.6)$ & $22(12.8)$ \\
\hline Frequency, leakage & 1.00 & $111(64.2)$ & $47(27.2)$ & $11(6.4)$ & $4(2.3)$ & 0 & $15(8.7)$ \\
\hline Stress & 1.12 & $90(52.9)$ & $52(30.6)$ & $24(14.1)$ & $4(2.4)$ & 0 & $28(16.5)$ \\
\hline Unexplained & 0.40 & $152(88.4)$ & $16(9.3)$ & $4(2.3)$ & 0 & 0 & $4(2.3)$ \\
\hline Nocturnal enuresis** & 0.30 & $163(99.4)$ & $1(0.6)$ & 0 & 0 & 0 & $0(0)$ \\
\hline
\end{tabular}

Mean dropout rate was 2.7 (range 0-9); questions 4-11 had a mean dropout of 0.4 (range 0-2)

*Mean dropout 6.3 (range 6-7)

** Mean dropout 9

${ }^{\text {a }}$ Frequency: never (0), rarely (1), sometimes (2), often (3), always $(\geq 4)$

${ }^{\mathrm{b}}$ Frequency: never (1-6), rarely (7-8), sometimes (9-10), often (11-12), always ( $\geq 13$ )

phase. Behavior when emptying the bladder could be important for understanding symptom origin and choosing the appropriate intervention for the LUTS patient. An easy intervention is to teach the patient a relaxed, optimal way of emptying the bladder. Symptoms due to a dysfunctional emptying pattern may be reduced with correction of the pattern. Therefore, this study may indicate the need to investigate a patient's voiding pattern to obtain an accurate picture and manage symptoms that may be due to dysfunctional toileting behavior.
Surprisingly, many young women reported urinary symptoms when using the definition of having symptoms at least sometimes or more often. However, there is a lack of definition for response alternatives, which can be confusing both for the responder and interpreter. On the other hand, they also reported having symptoms more frequently than occasionally. Our interpretation, therefore, is that they actually have symptoms, which is why data are summarized in this way. According to the definition of the ICS, for instance, urinary
Table 3 Toileting Behavior (TB) scale and the International Consultation on Incontinence Questionnaire Female Lower Urinary Tract Symptoms (ICIQFLUTS) (mean and in factors)

\begin{tabular}{llllll}
\hline Toileting behavior & Maximum & $\begin{array}{l}\text { Mean (SD) } \\
\text { Whole sample } \\
(n=173)\end{array}$ & $\begin{array}{l}\text { Mean (SD) } \\
\text { Nulliparous } \\
(n=146)\end{array}$ & $\begin{array}{l}\text { Mean (SD) } \\
\text { Parity } \\
(n=20)\end{array}$ & $P$ value* \\
\hline Place preference for voiding & 20 & $14.5(3.4)$ & $14.1(3.4)$ & $16.4(2.3)$ & 0.003 \\
Premature voiding & 25 & $10.0(4.0)$ & $9.8(3.9)$ & $11.1(4.3)$ & 0.180 \\
Delayed voiding & 15 & $7.9(2.5)$ & $7.8(2.3)$ & $9.0(3.2)$ & 0.024 \\
Straining voiding & 20 & $7.6(3.2)$ & $7.5(3.1)$ & $8.7(3.5)$ & 0.153 \\
Position preference for voiding & 10 & $3.3(1.4)$ & $3.2(1.8)$ & $3.4(1.5)$ & 0.751 \\
ICIQ-FLUTS & 16 & $5.3(2.6)$ & $5.0(2.6)$ & $6.8(2.0)$ & 0.000 \\
Frequency & 12 & $2.2(2.3)$ & $2.0(2.0)$ & $3.6(3.1)$ & 0.023 \\
Voiding & 20 & $1.8(2.2)$ & $1.5(2.1)$ & $3.6(2.5)$ & 0.000 \\
Incontinence & & & & & \\
\hline
\end{tabular}

Question about pregnancy, internal dropout $=7$

*Difference between nulliparous and parous calculated with Mann-Whitney $U$ test 
Table 4 Correlation between Toileting Behavior (TB) scale and International Consultation on Incontinence Questionnaire short form (ICIQ-SF)

\begin{tabular}{|c|c|c|c|c|c|}
\hline \multirow[t]{2}{*}{ ICIQ-FLUTS } & \multicolumn{5}{|c|}{ Toileting behavior } \\
\hline & $\begin{array}{l}\text { Place } \\
\text { preference } \\
\text { for voiding }\end{array}$ & $\begin{array}{l}\text { Premature } \\
\text { voiding }\end{array}$ & $\begin{array}{l}\text { Delayed } \\
\text { voiding }\end{array}$ & $\begin{array}{l}\text { Strain for } \\
\text { voiding }\end{array}$ & $\begin{array}{l}\text { Position for } \\
\text { voiding }\end{array}$ \\
\hline \multicolumn{6}{|l|}{ Frequency } \\
\hline $\begin{array}{l}\text { Spearman's rank } \\
\text { correlation }\end{array}$ & 0.224 & 0.226 & 0.223 & 0.310 & 0.134 \\
\hline$P$ value & 0.004 & 0.003 & 0.004 & $<0.001$ & $\mathrm{~ns}^{*}$ \\
\hline \multicolumn{6}{|l|}{ Voiding } \\
\hline $\begin{array}{l}\text { Spearman's rank } \\
\text { correlation }\end{array}$ & 0.169 & 0.250 & 0.315 & 0.646 & 0.071 \\
\hline$P$ value & 0.028 & 0.001 & $<0.001$ & $<0.001$ & $\mathrm{~ns}^{*}$ \\
\hline \multicolumn{6}{|l|}{ Incontinence } \\
\hline $\begin{array}{l}\text { Spearman's rank } \\
\text { correlation }\end{array}$ & 0.031 & 0.154 & 0.179 & 0.212 & 0.072 \\
\hline$P$ value & $\mathrm{ns}^{*}$ & 0.050 & 0.023 & 0.007 & $\mathrm{~ns}^{*}$ \\
\hline
\end{tabular}

NS nonsignificant (i.e., $p$ value $>0.05$ incontinence is "any urinary leakage," with no definition of how frequent it is [26]. Urinating nine times or more during the day, urgency, hesitancy, and straining were the most common symptoms. Van Breda et al. performed a study using
Table 5 Principal component analysis of Toileting Behavior (TB) scale to test construct validity and results of reliability test (Cronbach's alpha values)

\begin{tabular}{|c|c|c|c|c|c|c|}
\hline Questions & & $\begin{array}{l}\text { Premature } \\
\text { voiding }\end{array}$ & $\begin{array}{l}\text { Place } \\
\text { preference }\end{array}$ & $\begin{array}{l}\text { Straining } \\
\text { voiding }\end{array}$ & $\begin{array}{l}\text { Delayed } \\
\text { voiding }\end{array}$ & $\begin{array}{l}\text { Position } \\
\text { preference }\end{array}$ \\
\hline Worry about sanity in public toilets & 1 & & $0.763^{*}$ & & & \\
\hline Avoid public toilets & 2 & & $0.881^{*}$ & & & \\
\hline Empty the bladder at home & 3 & & $0.755^{*}$ & & & \\
\hline Try to wait until I come home & 4 & & $0.706^{*}$ & & & \\
\hline \multicolumn{7}{|l|}{ Void without desire: } \\
\hline At home & 5 & $0.629^{*}$ & & & & \\
\hline At work/school & 6 & $0.860 *$ & & & & \\
\hline Home of someone else & 7 & $0.831 *$ & & & & \\
\hline A public place & 8 & $0.827 *$ & & & & \\
\hline Just in case (preventive) & 9 & $0.758 *$ & & & & \\
\hline Try to delay voiding if I'm busy & 10 & & & & $0.857 *$ & \\
\hline $\begin{array}{l}\text { Restrain the desire as long as } \\
\text { possible }\end{array}$ & 11 & & & & $0.819 *$ & \\
\hline Restrain the desire at work/school & 12 & & & & $0.545^{*}$ & \\
\hline Strain to initiate urinating & 13 & & & $0.823 *$ & & \\
\hline $\begin{array}{l}\text { Strain during the whole urinating } \\
\text { process }\end{array}$ & 14 & & & $0.889^{*}$ & & \\
\hline $\begin{array}{l}\text { Strain to empty the bladder } \\
\text { completely }\end{array}$ & 15 & & & $0.836^{*}$ & & \\
\hline Strain to empty the bladder faster & 16 & & & $0.645 *$ & & \\
\hline Sit down on the seat & 17 & & & & & $0.643^{*}$ \\
\hline Hover over the toilet & 18 & & & & & $0.715^{*}$ \\
\hline Squat on the toilet & 19 & & & & & $0.751 *$ \\
\hline Eigen value & & 3.868 & 3.048 & 2.442 & 1.691 & 1.483 \\
\hline Explained variance (\%) & & 20.36 & 16.04 & 12.86 & 8.90 & 7.81 \\
\hline \multicolumn{7}{|l|}{ Total $66.0 \%$} \\
\hline Cronbach's alpha value & & 0.841 & 0.809 & 0.822 & 0.714 & 0.542 \\
\hline
\end{tabular}

*Factor loadings: values $>0.5$ are considered practically significant [21] 
ICIQ-FLUTS assessing 159 presumably healthy medical students aged 18-30 years [20]. They also summarized the alternatives in that way. Comparing our results showed that our group had more symptoms in all the investigated parameters. For example, urgency at least sometimes was reported by $34.2 \%$ of our group compared with $14.5 \%$ in their group. Pauwels et al. also found that middle-aged women had large bladder capacity and high bladder compliance, indicating that women tended to postpone toileting as long as possible [27]. Bladder pain was also quite common $(21 \%)$, but it is not clear what sort of pain. One explanation could be that cystitis problems in this age group are common, or irritative symptoms are from genitalia after sexual activity. Generally, our results showed higher prevalence rates compared with other studies, indicating that responders were women with more problems.

Higher scores in ICIQ-FLUTS subscales suggest a greater impact of separate symptoms for the patient, but there is no further information about how to interpret the summarized scores, as in the International Prostate Symptom Score (IPSS), in which symptom scores are classified as mild (0-7), moderate (8-19), and severe (20-35) for comparing symptom progression and severity and determining treatment [28].

The significant difference in all dimensions of urinary symptoms, not only incontinence, in the parity group with higher scores is interesting and to our knowledge not reported previously. However, the parity group was small, and this result must be viewed with caution. Parous women with LUTS often have increased laxity in passive-support structures, a deficit in the onset of the pelvic floor and strength to support the bladder neck when intra-abdominal pressure increases. Women with LUTS are also more likely to use straining voiding and for a longer time than healthy women with no symptoms [17]. The way straining is performed and whether LUTS is or is not present seem to be important. Structural changes due to childbirth might alter lower-urinary-tract function and behavior- or the impact of a behavior. More studies are needed in this regard.

Construct validity and reliability of the translated Swedish version of the TB scale showed similar results to the original. However, no other aspects of validity were tested, e.g., comparing results objective measures, which is difficult in a postal questionnaire survey. The TB scale was easy to use and questions well understood, as the internal dropout rate was low; > 95\% answered all questions. Factors in the questionnaire's subscales assessing toileting behavior made it possible to use to analyze relationships, in this case with ICIQ-FLUTS, even though this was not in the aim of instrument validation. Furthermore, it is feasible to assume that the translated version of the TB scale would be an aid in clinical practice to evaluate and modify toileting behavior, thus promoting good bladder health. To strengthen its generalizability, further testing is needed in community-dwelling and hospitalized populations.

Attaining the sample of young women seemed to be difficult, as the response rate was low. This must be taken into consideration when interpreting the results. Also, many questionnaires were returned as address unknown. One can assume that those who answered may have more problems than those who did not. However, that issue remains unknown. Dropout analysis showed a tendency of lower response rate among those living in the cities compared with those living in the country, but it is unclear what consequences that issue may have on results. Using e-mail instead of the postal system may have reached more women, but such data is not available in the population register in Sweden. Another option was to use Facebook or other social media, but a representative sample would not have been reached in that case either. Even though the intention was to have a representative sample from the population in this age group, we obtained a rather large sample and can therefore make some conclusions about young women and their urinary symptoms relative to toileting behavior. Studies among women in this age group are few, usually among selected groups only, but are not representative of the general population. However, the strength in this study was the finding of a relation between urinary symptoms and toileting behavior among younger women. To our knowledge, this has not yet been described in the literature.

\section{Conclusion}

Lower urinary tract symptoms were quite common in this group of young women. Toileting behaviors were also significantly related to urinary tract symptoms. Thus, the Toileting Behavior scale (TB scale) was useful for assessing this population, and the translated Swedish version showed good validity and reliability. Further research about the impact of toileting behavior is needed to understand the origin and development of LUTS and its treatment.

Acknowledgements The study was sponsored by the Hillivi Friis Foundation.

\section{Compliance with ethical standards}

\section{Conflicts of Interest None.}

Open Access This article is distributed under the terms of the Creative Commons Attribution 4.0 International License (http:// creativecommons.org/licenses/by/4.0/), which permits unrestricted use, distribution, and reproduction in any medium, provided you give appropriate credit to the original author(s) and the source, provide a link to the Creative Commons license, and indicate if changes were made.

\section{References}

1. Barnes PM, Maddocks A. Standards in school toilets - a questionnaire survey. J Public Health Med. 2002;24:85-7. 
2. Joelsson-Alm E, Nyman CR, Svensen C, Ulfvarson J. Micturition problems after bladder distension during hospitalization in Sweden: "I'm not ill, just damaged for the rest of my life". Nurs Res. 2014;63:418-25.

3. Lundblad B, Berg M, Hellstrom AL. Experiences of children treating functional bladder disturbances on schooldays. J Pediatr Urol. 2007;3:189-93.

4. Lundblad B, Hellstrom AL. Perceptions of school toilets as a cause for irregular toilet habits among schoolchildren aged 6 to 16 years. J Sch Health. 2005;75:125-8.

5. Norling M, Stenzelius K, Ekman N, Wennick A. High school students' experiences in school toilets or restrooms. J Sch Nurs. 2016;32:164-71.

6. Bower WF, Yip SK, Yeung CK. Dysfunctional elimination symptoms in childhood and adulthood. J Urol. 2005;174(4 Pt 2):1623-7. discussion 7-8.

7. Kistner M. Dysfunctional elimination behaviors and associated complications in school-age children. J Sch Nurs. 2009;25:108-16.

8. Soifer S, Nicaise G, Chancellor M, Gordon D. Paruresis or shy bladder syndrome: an unknown urologic malady? Urol Nurs. 2009;29:87-93.

9. Vythilingum B, Stein DJ, Soifer S. Is "shy bladder syndrome" a subtype of social anxiety disorder? A survey of people with paruresis. Depress Anxiety. 2002;16:84-7.

10. Coyne KS, Sexton CC, Thompson CL, Milsom I, Irwin D, Kopp ZS, et al. The prevalence of lower urinary tract symptoms (LUTS) in the USA, the UK and Sweden: results from the Epidemiology of LUTS (EpiLUTS) study. BJU Int. 2009;104:352-60.

11. Homma Y, Yamaguchi O, Hayashi K. Neurogenic Bladder Society C. Epidemiologic survey of lower urinary tract symptoms in Japan. Urology. 2006;68:560-4.

12. Irwin DE, Milsom I, Hunskaar S, Reilly K, Kopp Z, Herschorn S, et al. Population-based survey of urinary incontinence, overactive bladder, and other lower urinary tract symptoms in five countries: results of the EPIC study. Eur Urol. 2006;50:1306-14. discussion 1314-5.

13. Milsom I, Abrams P, Cardozo L, Roberts RG, Thuroff J, Wein AJ How widespread are the symptoms of an overactive bladder and how are they managed? A population-based prevalence study. BJU Int. 2001;87:760-6.

14. Norby B, Nordling J, Mortensen S. Lower urinary tract symptoms in the Danish population: a population-based study of symptom prevalence, health-care seeking behavior and prevalence of treatment in elderly males and females. Eur Urol. 2005;47:817-23.
15. Stewart WF, Van Rooyen JB, Cundiff GW, Abrams P, Herzog AR, Corey R, et al. Prevalence and burden of overactive bladder in the United States. World J Urol. 2003;20:327-36.

16. Zhu L, Lang J, Liu C, Han S, Huang J, Li X. The epidemiological study of women with urinary incontinence and risk factors for stress urinary incontinence in China. Menopause. 2009;16:831-6.

17. Wang K, Palmer MH. Women's toileting behaviour related to urinary elimination: concept analysis. J Adv Nurs. 2010;66:1874-84.

18. Wang K, Palmer MH. Development and validation of an instrument to assess women's toileting behavior related to urinary elimination: preliminary results. Nurs Res. 2011;60:158-64.

19. Avery K, Donovan J, Peters TJ, Shaw C, Gotoh M, Abrams P. ICIQ: a brief and robust measure for evaluating the symptoms and impact of urinary incontinence. Neurourol Urodyn. 2004;23: $322-30$.

20. van Breda HM, Bosch JL, de Kort LM. Hidden prevalence of lower urinary tract symptoms in healthy nulligravid young women. Int Urogynecol J. 2015;26:1637-43.

21. Hair J, Anderson R, Tatham R, Black W. Multivariate data analysis. London: Prentice Hall International; 1998.

22. Moore KH, Richmond DH, Sutherst JR, Imrie AH, Hutton JL. Crouching over the toilet seat: prevalence among British gynaecological outpatients and its effect upon micturition. Br J Obstet Gynaecol. 1991;98:569-72.

23. Pauwels E, De Laet K, De Wachter S, Wyndaele JJ. Healthy, middle-aged, history-free, continent women - do they strain to void? J Urol. 2006;175:1403-7.

24. Robinson D, Staskin D, Laterza R, Koebl H. Defining female voiding dysfunction: ICI-RS 2011. Neurourol Urodyn. 2012;31: 313-6.

25. King A, Goldman H. Bladder outlet obstruction in women: functional causes. Curr Urol Rep. 2014;15:436. doi:10.1007/s11934014-0436-Z.

26. Abrams P, Cardozo L, Fall M, Griffiths D, Rosier P, Ulmsten U, et al. The standardisation of terminology of lower urinary tract function: report from the Standardisation Sub-committee of the International Continence Society. Neurourol Urodyn. 2002;21:167-78.

27. Pauwels E, De Wachter S, Wyndaele JJ. Normality of bladder filling studied in symptom-free middle-aged women. J Urol. 2004;171:1567-70.

28. Barry MJ, Fowler Jr FJ, O'Leary MP, Bruskewitz RC, Holtgrewe HL, Mebust WK, et al. The American Urological Association symptom index for benign prostatic hyperplasia. The Measurement Committee of the American Urological Association. J Urol. 1992;148:1549-57. discussion 64. 